\title{
Enunciación
}

http://revistas.udistrital.edu.co/ojs/index.php/enunc

\section{La importancia de las inferencias indiciales en los procesos de comprensión lectora}

\author{
The Importance of Indexical Inferences in Reading Comprehension Processes
}

\author{
Éder García-Dussán ${ }^{1}$
}

Para citar este artículo: García-Dussán, É. (2014). La importancia de las inferencias indiciales en los procesos de comprensión lectora. Enunciación, 19(1), 116-134.

Recibido: 21 -abril-2014 / Aprobado: 14-julio-2014

\section{Resumen}

Frente a la creciente intranquilidad generada por los resultados deficientes en las pruebas nacionales e internacionales (Pisa, Saber), el artículo se propone defender la importancia del trabajo indiciario como estrategia que ayuda a la formación de lectores activos y más eficientes. Para lograr tal fin, primero se describen las posturas que se asumen frente al conflicto educativo en relación con el tema de la lectura, centrándose en posibilidades de superación desde la acción docente; luego se presenta un panorama teórico desarrollado desde concepciones psicológicas, lingüísticas, semióticas y culturales; finalmente, se da validez a una lectura apoyada de algunas premisas desarrolladas por Carlo Ginzburg y su paradigma de inferencias indiciales (2008); apuesta reflexiva que se ejemplifica en un texto de dominancia narrativa, lo cual deja ver cómo, en el acto lector, la planeación y el monitoreo que se centran en la manipulación con material textual implícito-asociativo admiten el acceso a recreaciones discursivas que privilegian la interpretación múltiple y la competencia discursiva.

Palabras clave: conocimientos previos, contextos, discurso, saber venatorio

\begin{abstract}
Faced with growing unease generated by the poor results in the national and international tests (Pisa, Saber), this article attempts to support the importance of indexical work as a strategy that helps formation of a more active and efficient reader. To achieve this, we first describe positions assumed against the educational conflict in relation to the subject of reading, focusing on possibilities for improvement from teaching activities; then we present a theoretical overview developed from psychological, linguistic, semiotic and cultural concepts; finally, we provide validity to a reading supported by some premises developed by Carlo Ginzburg and its paradigm of indexical inferences (2008); a reflexive theory exemplified in a narrative dominance text, which reveals how, in the act of reading, a planning and monitoring that focuses on handling with implicit-associative textual material, which supports the access to discursive recreations that favor multiple interpretation and discourse competence.
\end{abstract}

Keywords: prior knowledge, context, discourse, venatic knowledge

1 Filósofo de la Universidad Nacional de Colombia, magister en Lingüística Española del Instituto Caro y Cuervo. Hace parte del Consejo Superior de Investigaciones Científicas (CSIC) y del Instituto de la Lengua Española (ILE). Actualmente trabaja en la Maestría en Pedagogía de la Lengua Materna, de la Universidad Distrital Francisco José de Caldas. Pertenece al grupo de investigación Lenguaje, Cultura e Identidad. Correo electrónico: eagarciad@udistrital.edu.co 


\section{INTRODUCCIÓN}

Habitualmente todo lo relacionado con los procesos de lectura cobra una importancia radical cuando salen resultados estadísticos que muestran sus deficiencias. Por ejemplo, los resultados de pruebas internacionales de los estudiantes colombianos y su confirmación con estudios locales. En efecto, los informes internacionales del Programme for International Student Assessment (PISA) de 2009 a propósito de las formas eficientes de leer dejó a Colombia en el puesto 52 entre 65 países participantes: el $47 \%$ de los estudiantes participantes no logró el nivel mínimo adecuado de lectura para desempeñarse en la sociedad. Asimismo, los resultados de las pruebas SABER PRO de 2011 reveló que apenas el 34\% del total de los estudiantes evaluados, de unos 146.000, alcanzaba niveles aceptables de lectura interpretativa.

A esto se suman otras investigaciones afines, como la conocida a mediados de 2013 realizada por docentes de las universidades de Harvard, Los Andes y del Rosario, quienes a partir de los resultados de las pruebas PISA y SABER, señalaban que las desigualdades económicas y sociales generaban preocupantes brechas en la calidad de la educación que reciben los casi once millones de niños de básica y media en el país (Linares, 24-V-2013). Otras de las conclusiones eran:

- Asistir a un colegio privado urbano, ser hijo de padres con buen nivel educativo y recibir más horas de clase favorece el aprendizaje de los niños y jóvenes matriculados en la educación básica y media en Colombia. Todo lo contrario ocurre cuando los estudiantes son de estratos bajos, residen en áreas distantes a los centros urbanos o incluso estudian en media jornada.

- Los estudiantes con el menor puntaje promedio en las pruebas Saber 11 son los que más se matriculan en las licenciaturas relacionadas con la enseñanza de educación básica y media, contario a muchos países de Europa.

- En cuarenta y tres carreras, siete especialidades docentes se ubicaron en los últimos diez lugares en el área de comprensión lectora, según recientes pruebas Saber Pro.

- Los potenciales pedagogos también mostraron resultados deficientes en lengua extranjera; solo el $17 \%$ alcanzó niveles aceptables en el dominio del inglés.

A partir de este tipo de informaciones se ha vuelto habitual que los medios de comunicación y voces de autoridad del ámbito académico o de opinión generen discursos donde lo importante es dar con un culpable, a la mejor manera de una 'cacería de brujas', o bien encontrar 'chivos expiatorios' para exorcizar las culpas. Entonces, comienzan a determinarse focos causales de la situación. Básicamente, y sin mucho esfuerzo, se puede imputar la actualidad del asunto a la calidad del sistema educativo y el diseño de sus políticas, a la imperfecta preparación de los estudiantes o a la defectuosa formación de los profesores, pese a que en los últimos lustros se han invertido importantes dineros en la formación de maestros; de hecho, más que en cualquier sector del aparato público. Indudablemente, habrá posturas eclécticas que supongan la mixtura de las tres.

Así las cosas, desde un primer punto de vista, esta situación es posible mejorarla afectando el sistema escolar desde afuera, a través de políticas como la generación de una equidad escolar, fórmula visible de algunos países estrella en la pruebas Pisa como el caso de Finlandia, al nororiente de Europa, donde

No hay escuelas privadas. Tampoco hay universidades privadas, solo unas pocas instituciones privadas, y no se les permite que cobren; son financiadas por el Estado. Lo importante en Finlandia es que todos los docentes gozan de prestigio, paga decente y mucha responsabilidad. (Maya, 30-VIII-2013)

En nuestro caso, esto se reduce a mayores exigencias para los registros calificados que soliciten las universidades, con anuncios como la intensificación de las prácticas y la participación de maestros activos en la educación básica como profesores de los programas. (Cajiao, 7-IV-2014) 
Pese a lo anterior existen otras dos posibilidades explicativas. Hay una perspectiva que se concentra en el educando, la causa del fracaso escolar y los bajos rendimientos. Sobre este particular se revelan cifras generales y el directivo o el docente caen en un lugar común: tachar de incompetentes a sus estudiantes. Esto es habitual cuando solo se tienen en cuenta las habilidades y ejecución de sus tareas, así las falencias se traducen en un déficit

[...] que señala las carencias del estudiante sin comprometer la actividad del docente en su solución. Por esta vía, se cuestiona [...] las capacidades de los alumnos para emprender tareas que - puede inferirse por su nivel de formación- no están en capacidad de ejecutar con éxito. (Baquero, 2006, p.67)

Anudado a lo anterior, aparece la crítica a la racionalidad técnica del modelo vigente, Ilamada por otros "epistemología de la práctica", donde se enseña únicamente al educando a usar el saber para resolver problemas inmediatos; dicha epistemología hace que la educación se ordene y funcione a partir de unos currículos que dan información desde toda lógica posible. Luego, se producen iniciaciones tímidas a la aplicación de esos saberes, sin práctica reflexiva, sin arte de la construcción que elabora saberes concretos para problemas específicos y donde el tutor (desde una mirada calificadora y positivista) reduce todo esfuerzo a una instrumentalización y a un mero cambio de estrategia didáctica.

Finalmente, hay otra emergencia aclaratoria al respecto, quizá la más explotada y usada en los ensayos académicos de los docentes mismos, la cual sostiene que el mejoramiento del sistema educativo y de las habilidades de sus educandos está en manos del profesor; más exactamente, del constante perfeccionamiento sobre su acción pedagógica (métodos, interacciones, intenciones, prácticas comunicativas y evaluativas...). De esta suerte, el quebranto de la crisis educativa estaría en la formación docente para la práctica educativa y,
[...] esta no es posible con la simple aplicación del recetario prescrito que, aunque derivado de la experiencia del investigador profesional, es siempre contingente, toda vez que sus incursiones en el aula son en una amplia gama de aspectos, distintas a las del profesor. (Baquero, 2006, p.56)

Lo anterior implica que el docente se ampare en una actitud que involucre el rol de investigador y revise, por sí mismo, su práctica docente. Más directamente: que investigue desde el aula. Al respecto afirma el doctor en filosofía de Harvard Donald Schön, "¿de qué otro modo pueden los profesionales aprender a ser inteligentes, sino es precisamente a través de la reflexión sobre los dilemas de su práctica" (1992, p.11). Tal apuesta descansa en la capacidad analítica que tienen los docentes para superar sus dificultades, limitaciones y problemas; es más, se afirma con frecuencia que los buenos docentes, cuya meta no es la teoría, sino el desarrollo de supuestos para actuar en el aula de otra forma hacen esto cotidianamente.

Pues bien, concretando el asunto frente al problema de la baja comprensión lectora escolar, con frecuencia los estudios sobre los bajos rendimientos de los alumnos vinculados al proceso lector se agrupan en los mismos alumnos. Sin embargo, un análisis global del asunto involucra las concepciones que tienen los profesores sobre lo que implica el acto de leer. Por lo menos, se pueden reconocer cuatro concepciones cotidianas sobre la lectura que descansan en los protagonistas de la enseñanza, afectando sus prácticas y sus practicantes:

1. leer es decodificar signos gráficos y reproducir oralmente el texto; ${ }^{2}$

2 En adelante, para los propósitos de este artículo el concepto de texto es entendido como una unidad lingüística estructurada por niveles morfosintácticos y semánticos, y configurada por las condiciones generales de cohesión, coherencia, aceptabilidad, situacionalidad, informatividad e intertextualidad (De Beaugrande, 2002); mientras que el concepto de discurso es definido más como la confluencia de un texto cuando queda sujeto a los vaivenes de los contextos psicológicos, situacionales, socio-históricos, de producción y de precepción (Bolívar, 2007). 
2. Ios significados de la lectura están en el texto; el contexto no influye en la comprensión;

3. Ios conocimientos y experiencias previas del lector no son necesarias en la construcción del sentido del texto; $y$

4. es irrelevante el trabajo contextual e investigativo sobre informaciones que presenta el texto leído; es decir, no se valora el producto como un discurso.

Gracias a esto, en la alfabetización temprana se presenta una tendencia a enseñar a leer como si este fuera un acto pasivo, con el uso de textos no auténticos que ayudan a fomentar una práctica monótona y donde lo importante es deletrear palabras aisladas y des-contextualizadas en situaciones ficticias de uso y con actitudes muy lejanas frente a la búsqueda de un sentido; $y$, a su vez, sin referencialidad a una pesquisa con ayuda de índices textuales (Flórez y Gómez, 2013). Entonces, se repite el escenario complejo y repetitivo donde los profesores escogen una lectura, los estudiantes leen fragmentos mientras el resto la sigue $y$, si comete algún error de entonación, pronunciación, pausas o similares, el profesor interviene de forma correctiva, llevando el esfuerzo a ejercicios gramaticales (Solé, 1992). Esto, a larga data, propicia estudiantes que leen para realizar una exposición o para responder una evaluación escrita u oral; pero también, como se nota rápidamente, acciones donde está ausente el asentamiento de un proceso comunicativo, lo cual implica intenciones y beneficiarios. Dicho de otro modo, se ha asistido tradicionalmente a una didáctica lectora que apunta a la lectura y no a las estrategias que potencian una comprensión significativa; o lo que es igual, a la relación entre lo que sabe el lector y lo que el texto aporta dentro de marcos socioculturales, geográficos y emocionales determinados (Pérez y Rodríguez, 2012).

A este panorama se han venido sumando resultados de otros estudios, los cuales muestran que los estudiantes, en fases escolares tardías, le dan un valor sustancial a la toma de apuntes como un elemento que favorece el aprendizaje autónomo, evidenciando que lo que más se lee y lo que realmente cuenta a la hora de una evaluación son, en su orden: apuntes de clase propios, materiales elaborados por el profesor y páginas web; mientras lo que menos se lee son apuntes de clase de otro compañero y novelas literarias, evidenciando que existen formas de lectura no reconocidas aún en los contextos académicos (Molina, 2012). Entonces, se pasa de la ya vetusta estrategia del corte y pegue, a la de la foto instantánea que se guarda en la memoria del smartphone.

Pues bien, ante todo este panorama, la pregunta escueta y urgente que surge es ¿cómo, desde la acción central del profesor es posible aportar a la solución de este espinoso asunto? Para contribuir con una respuesta posible, revisaremos primero los aportes más sobresalientes de las dimensiones o concepciones teóricas sobre el proceso lector, a fin de situar en esa constelación de antecedentes el territorio de la estructura indiciaria de los discursos y, posteriormente, exploraremos y explotaremos este aspecto como herramienta que puede usar el profesor en su quehacer cotidiano con los educandos, cuestión que se materializará con un ejemplo, aprovechando un texto breve en extensión, pero enérgico en su significación.

\section{Algunos discursos sobre la comprensión de discursos}

Con la instauración de la psicología cognitiva en el siglo XX e inspirada en la empresa chomskiana, surgieron modelos didácticos de maduración y fortalecimiento lector que han puesto como elemento primario los conocimientos adquiridos a través de los textos trabajados previamente por parte del lector; de suerte que la construcción del sentido se sienta en una interacción entre texto y lector (modelo interactivo). Así las cosas, el lector explora, identifica, ensambla saberes $y$, de esta forma, re-construye sentidos (Goodman, 1996). En una palabra, el lector es quien activa estrategias cognitivas para lograr dar un sentido a lo leído, 
siendo vital las de aclarar el fin de su actividad y sus expectativas para enfrentar un texto preciso en un contexto particular y así movilizar experiencias previas (Jolibert y Sraïki, 2006). Esto incluye la identificación de propiedades en los diversos niveles lingüísticos del texto y el ejercicio de procesar inferencias ${ }^{3}$ a partir de los signos indiciales que, a la postre, permitirán al lector construir hipótesis sobre la intención del autor y su verificación en acciones de monitoreo y comparación continuas.

Pero, a medida que avanza la lectura se activan diferentes líneas de pensamiento. La cultura, la sociedad que rodea al lector, la situación y el propósito que lo lleva a ese texto particular en ese momento particular, sus supuestos y preocupaciones particulares; incluso, su estado físico y anímico influyen en el logro de un sentido personal de su ejercicio lector (modelo transaccional). El resultado de esto es, la mayor de las veces, la construcción de un modelo mental sobre el texto. De esta suerte, se supera la idea de linealidad por la de secuencialidad y de retroalimentación entre superestructuras y microestructuras (modelo psicolingüístico cognitivo). Así las cosas, el sentido se logra paulatinamente cuando el lector, manipulando su saber super-estructural de los textos (también Ilamados esqueletos o esquemas textuales), va activando una gama estratégica de progresión cognitiva que comienza en la supresión o eliminación de información irrelevante, hasta la construcción o introducción de información nueva a partir de la presente en el texto-base, pasando por un puente Ilamado generalización o integración de varias proposiciones en unas pocas, gracias a su carácter temático (van Dijk, 1995).

Por esta vía, el éxito de una comprensión descansa en la posibilidad de establecer nuevos nexos

3 Inferir (del latín infiero) significa Ilevar hacia; esto es, llegar a algo nuevo a partir de lo dado previamente. Es pasar de un antecedente a un consecuente. Braslavsky define las inferencias como las referidas a "significados implícitos que están entre líneas y se inducen como probables a partir de los contenidos explícitos. Son elaboraciones que suponen vincular ideas, Ilenar lagunas, hacer conjeturas, formular hipótesis, imaginar más allá de lo implícito..." (2013, p.155). o nuevas estructuras de sentido partiendo de lo explícito de un texto. Como se nota, en la base de esto descansa la conocida metáfora del iceberg, recordada por Rosemblatt (modelo transaccional) y usada como sentido total de una textura para un sujeto: lo visible es el aspecto público o 'superficial', pero que descansa sobre la oculta o escondida. La pericia de un lector experto consiste, entonces, en pasar de la parte visible a la parte disimulada para desentrañar el contenido 'profundo' del texto intervenido. En esta labor, también es importante tanto el uso de estrategias cognitivas, que apuntan a aumentar y mejorar los productos de la actividad cognitiva, como el uso de estrategias meta-cognitivas, empleadas para planificar, supervisar y evaluar la aplicación de las primeras (Osses, 2008).

En esa medida, con todo este panorama de perspectivas o enfoques sobre el acto lector, tenemos el perfil de un leedor activo y motivado, que no puede no dejar de hacer conexiones implícitas, ni de cubrir huecos y poner a prueba sus pronósticos (modelo sociosemiótico). Es por eso que el investigador italiano Umberto Eco indica que la lectura es un proceso en el que el lector coopera con el texto, proporcionándole una interpretación; y para ello se vale de sus competencias circunstancial y enciclopedia (o conocimientos previos), a fin de actualizar el contenido que tiene en frente; es decir, completa los espacios en blanco que encuentra en los entresijos texturales, plagados de elementos no dichos o no manifiestos en la superficie; dicho de otro modo, de espacios de indeterminación que deben ser restaurados. Este proceso de actualización beneficia al lector, contribuyendo con la formación de su competencia y haciéndolo partícipe de la obra; de suerte que es el lector quien da sentido a la obra, la cual en sí misma no pasa de ser una cadena organizada de signos negros compensados en unas páginas. Eco lo dice así: "[...] un texto, tal como aparece en su superficie o manifestación lingüística, representa una cadena de artificios expresivos que el destinatario debe actualizar" (1981, p.71). 
Todos estos aportes se pueden difundir como fundamentos seguros para la construcción de una posible didáctica de la lectura, y, sumado a esto, se pueden complementar con elementos propios de las posturas de Vigotsky (modelo sociocultural). Desde esta dimensión, un lector activo es quien enfrenta múltiples posibilidades de interpretación y quien, partiendo del texto pero accediendo al discurso, recorre lo múltiple y situado, haciendo intervenir los contextos (situacional, cognitivo, físico, cultural...). Esto permite entender que el sujeto-lector se juega con la interacción compleja la construcción del sentido. Por ello, lo significativo del texto reposa en el discurso, que nunca puede ser unívoco, sino relativo (Cairney, 1992). Digamos, entonces, que el panorama aquí desplegado se completa cuando se ve que la comprensión exige una negociación entre el lector, el texto y el contexto. Esto delinea una forma concreta de entender el acto de los lectores activos, cifrado en apuestas literales y no literales, implícitas y explícitas, paradigmáticas y sintagmáticas, textuales y contextuales (Cárdenas, 2006). Toda esta miscelánea teorética nos permite concluir que:

[...] La lectura debe entenderse como un proceso intencional, gradual y estratégico de creación de Sentido a partir de la interacción del lector con el texto en un contexto particular, interacción mediada por su propósito de lectura, sus expectativas y su conocimiento previo. Esta interacción, lleva al lector a involucrarse en una serie de procesos inferenciales necesarios para ir construyendo, a medida que va leyendo, una representación de lo que el texto describe [...]. (López, 2002, p.228)

Además, es importante testimoniar aquello mismo que el profesor pretende enseñar. La razón más fuerte para que el docente aporte su experiencia en la lectura de sus estudiantes es que tiene una disposición de repertorios, construidos a lo largo de su formación, que le permitirían aportar aquello que la doctora de la Universidad Autónoma de Madrid, Paula Carlino, Ilama "hojas de ruta y lentes" que auxilian la acción de enfocar lo cardinal en los textos:

[...] al planificar las propuestas de lectura, no es suficiente que los profesores decidamos qué han de leer los alumnos; también resulta necesario que tomemos consciencia de los propósitos que cumple la bibliografía elegida según los objetivos de la asignatura, a fin de comunicar a nuestros estudiantes por qué les pedimos que lean y para qué. $(2007$, p.72)

Pues bien, aunando las cualidades más sobresalientes del esfuerzo realizado hasta ahora desde los modelos puestos a dialogar atrás, se cree que son cinco los principios fundamentales que se pueden compendiar de las perspectivas presentadas, a saber:

(1) Leer es reconstruir activamente el sentido de un texto y no una acción receptiva (Medina y Bruzual, 2006);

(2) para alcanzar un sentido, el lector no debe olvidar que su relación de actualización con el texto (proceso bottom-up o top-down), sin olvidar nunca el contexto, lo cual puede ir de forma ascendente (del texto al lector) o de forma descendente (del lector al texto);

(3) toda lectura pasa necesariamente por una fase interpretativa, puesto que la información que se extrae de un texto depende tanto de este como de lo que el lector aporta en su labor inter y extra textuales (Lerner, 1985);

(4) la búsqueda de la comprensión pasa por una lectura selectiva y auto-regulada, que fortalezca labores de predicción-verificación de hipótesis a partir de claves o pistas que el texto proporciona (Smith, 1984); $y$,

(5) como lo indicaron en su momento Ferreiro y Gómez (1986), en todo buen lector interviene la creación, sus aportes propios y su astucia para trabajar con indicios y pistas. 


\section{Propuesta de un camino lector}

Como es notorio, al relacionar elementos sobresalientes desgajados de las concepciones psicolingüística, sociosemiótica y sociocultural hay algo común en las actividades de un lector activo o leedor, a saber: el reconocimiento de la labor inferencial y el tratamiento de estas con material indicial o indexical. Baste recordar que Brunner hace más de 60 años ya denominaba a la mente humana como una 'máquina de inferencias'. En términos de las clasificaciones de los psicolingüistas, estaríamos referenciando el terreno de las inferencias basadas en el conocimiento (León, 2003) o de las abducciones hipo-codificadas (Eco 1992). Sin embargo, en la escuela dichas taxonomías muchas veces no pasan de ser una lista de elementos teóricos inexplotados en la labor de auxiliar las habilidades lectoras en y para los educandos, dada la tendencia de divorciar teoría y praxis.

Ahora, si partimos de la noción general de que todo discurso es un tejido de signos (tex-jido), cuyos hilos entretejen símbolos, íconos e indicios, debemos suponer que estos se con-funden en la unidad inmediata llamada 'texto'. No obstante, de las clases de signos resaltamos substancialmente el indicio, un signo bien particular caracterizado porque está motivado por la contigüidad, cualidad que permite que alguien infiera algo que no es visible de forma inmediata (recuérdese aquí la analogía con la figura del iceberg); de suerte que, frente a su cara significante o indicante, aparece la cara significada o indicado gracias a un proceso de 'augurio' proverbialmente condicionado. Así, por ejemplo, la huella de la mano en la mejilla es testimonio de la bofetada; la quemadura recuerda la exposición al sol; el calor de la cama y el hundimiento de las almohadas, una presunción legal del adulterio; el musgo en la ventana, la humedad; asimismo las nubes grises, donde no es perceptible aún la Iluvia, augura el chubasco, etcétera (Klinkenberg, 2006).

En este orden de ideas, debemos al historiador italiano Carlo Ginzburg (2008) el recurso teórico del paradigma indiciario, quien sostiene que el nacimiento de este paradigma se remonta a los primitivos antepasados cazadores en la prehistoria, especialmente en la época en que la humanidad vivió de la caza. Para sobrevivir, ellos tuvieron que aprender a re-construir el aspecto y los movimientos de una presa invisible a través de sus rastros. Entonces, las huellas en terreno blando, las ramitas desgarradas, las heces y desechos animales, pelos, plumas o salivazos trenzados en elementos de la naturaleza, ciertos olores o charcos enturbiados, etcétera, fueron de gran importancia, pues les permitieron recrear un hecho vital e inmediato a partir de tales huellas, síntomas e indicios:

El cazador habría sido el primero en 'contar historia', porque era el único que se hallaba en condiciones de leer, en los rastros mudos (cuando no imperceptibles) dejados por la presa, una serie coherente de acontecimientos. (Ginzburg, 2008, p.194)

Este tipo de saber es el venatorio, esto es el conocimiento de reglas para cazar exitosamente en el monte, caracterizado por la habilidad de pasar de hechos observables inmediatamente y aparentemente insignificantes a una realidad compleja, predictiva y vital. Como se nota, este rasgo del saber venatorio en los primitivos rastreadores de indicios permite marcar una relación de su conocimiento previo con procesos de adivinación, predicción o pronóstico, pues a partir de un hecho manifiesto, alguien prevé otra cosa asociada con el estímulo primero. De hecho, es un tipo de saber del que también se alimenta la ciencia:

La ciencia no es un sistema de enunciados seguros y bien asentados, ni uno que avanzase firmemente hacia el estado final. Nuestra ciencia no es conocimiento; nunca puede pretender que ha alcanzado la verdad, ni siquiera el sustituto de esta, que es la probabilidad... no sabemos: solo podemos adivinar. (Popper, 1977, p.259) 
Aún más, el paradigma indiciario, lejos de describir un hecho fundante de los primeros padres del homo sapiens, es un hecho estratégico de supervivencia de la especie y mantiene su eficacia y fuerza procedimental a tal punto que ha ido dejando su impronta en distintas disciplinas. Se puede observar, por ejemplo, en el arte de los bibliotecarios, quienes lo usaban para descubrir de qué fecha databan ciertos manuscritos del griego o del latín y así reconocer su autenticidad o conjeturar a qué autor pertenecían; pero también los estudios que comienzan a realizarse sobre las formas en la escritura, donde ciertos expertos que se pusieron a estudiar cómo era el enlace de una letra con otra y los estilos del dibujo de la letra, montaron el concepto de carácter, el cual, al enlazarse el carácter de la letra y la personalidad del escritor, selló el nacimiento de la grafología y paralelamente el de la filología; y, mucho más reciente, la correspondencia de este paradigma se evidencia con los procedimientos forenses de Sherlock Holmes y las hipótesis freudianas del trabajo discursivo del inconsciente. Vemos así cómo, en suma, estamos frente a métodos conjeturales cuya base es el saber de la montería.

Llevando esto al terreno del acto lector, tenemos un sujeto capaz de actuar a la mejor manera de un investigador forense; es decir, como aquel que recorriendo un tejido, descubre a través de una labor conjetural huellas que le permiten reconstruir el escenario original de una transgresión y darle sentido público a un evento que, por naturaleza de lo social, está vedado. Claramente, para lograr esto se necesita de un entrenamiento y de ser muy sagaz en el reconocimiento del andamiaje indiciario, tal como lo demuestran las aventuras del personaje de Conan Doyle. Aquí, una clave para su tratamiento es más cognitiva que mecánica, y depende mucho de la capacidad que tenga el lector de 'adivinar' o 'predecir' que alguna marca textual es una clave discursiva que esconde 'algo más', un 'querer decir'. Es decir que el paradigma indiciario ayuda a actuar con una atención focalizada frente a un detalle que dispara un mundo latente o enmascarado: 'ojo clínico' y 'buen olfato'. Así, pues, frente a la labor de 'husmear indicios' subyace la tendencia a los detalles marginales e irrelevantes, que en principio pueden considerarse triviales y carentes de importancia, porque en los trazos textuales más descuidados es en los que se encierra la clave para acceder a una realidad más recóndita que, de lo contrario, sería inabordable.

Según la experiencia, en el orbe discursivo actúan como indicios algunas determinaciones léxicas (espacialmente verbos, que admiten varias acepciones con las que juega el autor del texto), construcciones sintácticas concretas (ideas que arrastran proposiciones que consienten el carácter conjetural), detalles semánticos específicos (adjetivos calificativos, afectivos, despectivos, etcétera), informaciones implícitas, y muy especialmente, el título, porque este elemento es definitorio de la coherencia global del texto y asegura la unidad e intención del texto. Además, al tomar como rutina y estrategia lectora la detección de indicios, es útil preguntarle al texto continuamente, tratarlo como un ente activo que exige del lector la activación de una cierta 'malicia indígena'. Esta labor es importante en la medida en que guía la búsqueda de la información extratextual, pues no es posible la interpretación sin estos movimientos, sin las salidas del texto y los retornos al texto, pues es claro que nada sale de la nada y que todo texto es, finalmente, un reflejo de las condiciones socio-históricas de su producción; esto es, la confirmación de que todo texto deviene discurso (García-Dussán, 2008).

Ahora bien, solo es posible comenzar a trascender el texto y lograr, al menos, una hipótesis de sentido cuando se une la información extratextual con lo que aparece en el texto seleccionado como material indiciario. Las asociaciones entre significantes son en principio infinitas (semiosis ilimitada); por tanto, solo es posible establecer asociaciones correctas con ayuda de la información que solidariamente viene del exterior. De esta forma, tal labor restringe las múltiples hipótesis y el riesgo continuo de la sobre-interpretación, además le aporta validez interna; de lo contrario, el ejercicio se reduce a una mera especulación sin fundamento investigativo. Ahora, la tarea de seleccionar indicios es el presupuesto que apoya la cuestión ¿qué debe buscarse fuera?, y una 
vez se hace ese primer empalme, resulta más sencillo y seguro relacionar el texto y los contextos. Para alcanzar este proceso, se sugiere 'abrir los ojos' a dos tipos de relaciones:

- Relaciones contextuales. Tras movimientos topdown y bottom-up ${ }^{4}$, se agrupan indicios a través de informaciones contextuales. El texto comienza a re-armarse, luego de su primera acción de descomposición/análisis, a través de elementos externos que sirven como 'cemento indiciario'.

- Relaciones intertextuales. Se establecen relaciones con evaluaciones obtenidas del trabajo abductivo con otros textos, ora porque son del mismo autor, ora porque recurren a la misma matriz (sociológica, antropológica, política, conductual, de género, etcétera) que permite su significancia.

Resumiendo, tenemos que para leer y comprender desde el paradigma indiciario, se deben tener en cuenta los siguientes principios (P1-P4):
P1: todo discurso con lo que dice quiere decir algo más (el discurso se presenta como un iceberg; así, todo producto cultural se concibe en su doble naturaleza funcional).

P2: ningún productor textual afirma algo desde la nada (está inscrito en coordenadas físicas, socio-históricas, socio-políticas, culturales y cognitivas).

P3: pese a A2, el discurso no se limita a las determinaciones contextuales (todo discurso es una obra abierta y atemporal; que captura, incluso, al propio lector, que nunca es el mismo en ninguna época).

P4: el leedor es co-autor del discurso (el leedor Ilena vacíos, con-forma, re-configura y completa y/o actualiza los contenidos de la forma textural con sus propios 'horizontes de sentido').

Los procesos cognitivos y las estrategias que se llevan a cabo mientras se lee se pueden resumir en dos grandes etapas (en ellos, el leedor activa siempre unos conocimientos o saberes previos): Tabla 1.

Tabla1. Etapas de leedor

\begin{tabular}{lll}
\hline \multicolumn{1}{c}{ Tipo de labor } & \multicolumn{1}{c}{ Acciones básicas } & \multicolumn{1}{c}{ Cualidad } \\
\hline $\begin{array}{l}\text { Intra-textual con la len- } \\
\text { gua-sistema } \\
\text { (El decir o lo que es) }\end{array}$ & $\begin{array}{l}\text { 1. Se separan diferentes los componentes del } \\
\text { texto }\end{array}$ & $\begin{array}{l}\text { Fase crítica o de tensión (prima la } \\
\text { sorpresa, el silencio y el goce de lo } \\
\text { real del cuerpo textual) }\end{array}$ \\
& $\begin{array}{l}\text { 2. Se examinan sus propiedades y funciones } \\
\text { en cada nivel lingüístico, privilegiando el } \\
\text { material indicial bajo preguntas como: ¿Qué } \\
\text { elementos o huellas textuales permiten asociar } \\
\text { implicaturas socioculturales (sobreentendidos, } \\
\text { presupuestos, informaciones históricamente } \\
\text { determinadas)? }\end{array}$ & \\
\hline $\begin{array}{l}\text { Extra e inter textual con el } \\
\text { habla } \\
\text { (Coordenadas del decir o }\end{array}$ & $\begin{array}{l}\text { 1. El texto se abre al mundo que redescribe y } \\
\text { que recrea... "el texto se hace discurso" }\end{array}$ & $\begin{array}{l}\text { Fase hermenéutica o de relajación } \\
\text { (sobresalen caminos decibles de } \\
\text { sentido; el placer se manifiesta en } \\
\text { hipótesis de sentidos) }\end{array}$ \\
\hline
\end{tabular}

Fuente: elaboración propia.

4 Proceso de inferior a superior (bottom-up), donde se parte palabras para construir frases y proceso de superior a inferior (top-down), donde se parte de la información global y se extraen significados parciales. 
De esta suerte, la interpretación posible se proyecta como una operación que reduce el acto lector a una arte de la investigación y que permite avanzar hacia una traducción. Esto hace que, en suma, en esta etapa leer se defina como un acto que genera resignificación de significantes; una detención de la semiosis infinita; pero, también, un acto transcultural. En esto, debe tenerse en cuenta que:

- Lo importante no es leer, sino re-leer a la luz de lo investigado.

- La mejor actitud del leedor es la del sujeto resignado; lo cual implica:

1. Ponerse, voluntariamente, en las manos de los indicios. Leer es igual que rezar: solo sirve al que cree (en su olfato y su ojo clínico)

2. Tener paciencia en el ejercicio explicativo (ex-plegar) y saber que hay que generar un cadarzo.

Finalmente, se debe culminar el proceso lector con la materialización de, mínimo, una hipótesis de sentido, lo cual está determinado por cuatro avisos o consejos, a saber:

- La actitud del leedor radica en que no se asusta frente a los baches culturales y la falta de conocimiento, pues su acto se reduce a buscar pacientemente (Rumiar, diría Nietzsche). Comprender es, en suma, una superación continua de las barreras culturales de conocimiento.

- Como alguna vez afirmaría el lingüista Patrick Charaudeau "en asuntos del discurso, un gato nunca es un gato". Esta querella cobra sentido ya que comprender aquí se reduce a la eficiencia de una traducción de la lengua pública y visible a la lengua privada o disfrazada: $\mathbf{X}=\mathbf{Y}$. Según Peirce, traducir implica adbucir, ${ }^{5}$ esto es, generar

5 Adbucir (del latín abdúcere; ab: lejos; dúcere: llevar) significa apartar o separar una proposición dentro del conjunto de las evidentes para ubicarla en el plano de lo probable. conjeturas o hipótesis de sentido a partir del saber del otro o de lo otro

- La traducción oscila entre lo exacto y lo inexacto: ¿Hay traducciones exactas?: toda traducción es anexacta y negociable. Es aquí donde el concepto de 'rigor elástico' auxilia la función lectora. Siguiendo el modelo de la semiótica médica, Ginzburg sostiene que de lo que se trata es de llegar a un fin práctico, posible si encuentra una regla de equivalencias $(X=Y)$ que pueda explicar tales resultados; lo cual significa que el médico debe echar mano a ciertas creencias prefijadas para interpretar qué es lo que le está pasando a su doliente, dependiendo de un contexto situacional e histórico, además de un contexto cognitivo o almacén de saberes.

- El traductor es un lector excesivo, obsesivo y minucioso; es el que presta a un texto una atención que a veces ni siquiera el autor le ha dedicado.

\section{Ejemplo de un trabajo indiciario con un texto de dominancia narrativa}

Ahora, para darle un dinamismo que a su vez demuestre la viabilidad, se tomará un breve texto del escritor cubano Guillermo Cabrera Infante a quien se le recuerda, preferentemente, por su novela Tres tristes tigres, aparecida hacia 1968 en Londres. Como se sabe, esta obra relata la vida nocturna de tres jóvenes en La Habana de 1958, y se caracteriza por un uso perspicaz y agudo del habla dialectal cubana, que le permite introducir desde trabalenguas infantiles (Tres tristes tigres triscan trigo en un trigal), hasta coloquialismos cubanos ("El libro está escrito en cubano", indica el autor), que terminan siendo intromisiones en las jergas populares de su país natal.

Para Cabrera Infante, lo importante era jugar con el lenguaje. De hecho, él mismo afirmaba que su labor escrituraria era un juego, pues los 'juegos de palabra' son palabras cuyo sentido depende del juego instaurado en los significantes mismos, siendo el lector quien activa sus cadenas de movimientos $y$, de paso, sus reglas de interpretación (Mac 
Adam, 1996). De esta suerte, en sus obras hay un cierto desdén por el contenido y solo basta con la belleza de la forma, con la que se juega hasta producir sentidos o, la mayor de las veces, revelar una crítica de su aprehensión a través del uso de jitanjáforas, pues como el mismo autor lo teorizó en las páginas de Tres tristes tigres, la propuesta de la literatura en la novela es proponer un mundo oral, conversando, articulando significantes, porque esa es la 'literatura viva' que se presume es mejor oírla que leerla (Cabrera, 1967, Advertencia) y que con humor, sátira y desarreglados episodios narrativos, recuerda al humorista y escritor inglés Laurence Sterne y su obra La vida y las opiniones del cabaIlero Tristram Shandy.

Manifiestamente, los esfuerzos literarios del escritor cubano se encausan en esta intención, la que no por casualidad se encuentra en su obra de 1976, Exorcismos de esti(l)o, una miscelánea de narraciones que mezclan un carácter empírico, al tiempo que deja notar una entrega total a las investigaciones que refieren los límites y preceptos de la lengua española. Compuesto de piezas liliputienses, en su libro Exorcismos de Esti(l)o no hay narración que no estimule en el lector emociones de toda índole, creando tanto experiencias estéticas variadas como tensión, justo aquello que según Umberto Eco genera a su vez meditación; esto es, verdaderos mensajes estéticos (Eco, 1986); indudable en el siguiente relato del autor, cualificado porque no tiene título:

SI EL DICCIONARIO MANUAL E ILUSTRADO DE LA LENGUA ESPAÑOLA, DE LA REAL ACADEMIA, LIMPIARA, FIJARA Y DIERA ESPLENDOR A LA MUJER TAL COMO DEFINE AL PERRO, EN LA EDICIÓN DE ESPASA CALPE DE 1950, EN LA PÁGINA MIL CIENTO SETENTA Y TRES...

Mujer 1. f. Mamífero omnívoro doméstico, de tamaño, forma y pelaje muy diversos, según las razas, pero siempre con las mamas más pequeñas que las nalgas, las cuales suele asentar la hembra para orinar. Tiene oído muy fino y es inteligente y muy leal al hombre. (Cabrera Infante, 1976, p.56)
Estamos frente a un texto que tiene dos partes reconocibles gracias al juego de su presentación material, pero también un laberinto de sentidos por descubrir. ¿Cómo acceder a sus entrañas?, ¿con qué intención Cabrera Infante avanza tal comparación molesta?, ¿cómo manipular la materia significante del relato para lograr una comprensión que supere la tensión generada? Para resolver estas cuestiones, se tendrán en cuenta los fundamentos y recomendaciones del paradigma indiciario, que auxiliará el trabajo de análisis e interpretación del relato de Cabrera Infante y que actuará como un apoyo para desenmascarar su contenido latente.

Pues bien, cuando se concentra el lector en el primer párrafo del cuento, se da cuenta de que se trata de una compleja estructura condicional contra-factual de la forma si se da una situación, entonces debe darse una instrucción-acción; por lo tanto, la acción expresada es hipotética, esto es, se trata de un evento que no ocurre en lo real, pero que se establece para obtener una consecuencia de su posible relación. Como se nota, en el relato la información de la instrucción o consecuente de la estructura (si X entonces Y) está ocupada por el signo ortográfico de los puntos suspensivos, usados principalmente para expresar intriga $y / o$ duda, o bien para reemplazar un texto conocido por gran parte de la población, o también las dos de forma simultánea. De esta suerte, parece que hay una invitación explícita por parte del autor para que el lector complete la información, acudiendo a su saber contextual.

Lo interesante de tal invitación sugerida en la elisión del consecuente de la estructura condicional es que aparece realizada efectivamente la instrucción-acción, esto es, aparece definida mujer con los elementos lexicográficos propios de la definición de perro, respetando afinadamente los componentes propios de un artículo lexicográfico, tal como se ejecuta en las plantillas de la Real Academia Española (RAE), a saber: la entrada lexicográfica (mujer), el Número de acepción (1.), la Información gramatical (f.) y la definición, por cierto, clara, precisa y definiendo un sustantivo 
por otro sustantivo, como se pide regularmente (Mamífero omnívoro doméstico, de tamaño, forma y pelaje muy diversos, según las razas, pero siempre con las mamas más pequeñas que las nalgas, las cuales suele asentar la hembra para orinar. Tiene oído muy fino y es inteligente y muy leal al hombre). Esto no deja lugar a dudas sobre su correcta definición.

A simple vista, desde lo literal del producto se trataría de un ejercicio que tiene la intención de vilipendiar a la mujer, aprovechando algo que no ejecuta la RAE a través del Diccionario de la Real Academia Española (DRAE); pero, para un lector ladino pegado al detalle o, como afirma Ginzburg, atento a los "pequeños discernimientos" o las "materiales pequeñeces" (2008, p 209; p.213) se está escondiendo algo más profundo y disfrazado. Ahora, para "sacar a flote" ese 'querer decir', es importante actuar y ayudarse de la arquitectura indiciaria que ofrece el micro-relato. Y, en ese rol, es posible entender que las huellas empotradas en la cadena significante son material conjetural que permite avanzar hacia una lectura interpretativa del relato en cuestión. Así por caso, el razonamiento condicional presente, el uso de grafías en minúscula y mayúscula o la ausencia de informaciones. Es así como se entiende la aseveración de Ginzburg cuando afirma que antaño, una cosa era

analizar huellas, astros, heces, catarros bronquiales, córneas, pulsaciones, terrenos nevados o cenizas de cigarrillos; otra analizar grafías, obras pictóricas o razonamientos. La distinción entre naturaleza (inanimada o viva) y cultura es fundamental, mucho más, en verdad, que la distinción infinitamente más superficial y cambiante entre las distintas disciplinas. (2008, p.213)

Esto es, ajustar el ojo del lector a los signos culturalmente condicionados. Ahora bien, al atender al objeto de atención, se pueden puntualizar que cuatro son las marcas indiciarias que resultan importantes para su exploración textual:
1. El diccionario manual e ilustrado de la lengua española, en su edición de 1950;

2. La información del condicional "[...] LIMPIARA, FIJARA Y DIERA ESPLENDOR A LA MUJER TAL COMO DEFINE AL PERRO";

3. La ausencia de título para el micro-relato (una cadena de significantes ausentes); $y$,

4. El título, en este caso, la ausencia de un título.

Justamente aquí empieza el ejercicio de investigación y de asociaciones intra y extra textuales. Aunque, en adelante, este rastreo parezca más bien una labor centrada en metódicas lexicográficas, más bien es un pretexto para darle cuerpo a un elemento que se ha seleccionado como clave indicial y un ejemplo de lo moroso que puede ser con-figurar un elemento intratextual con información extratextual. Pues bien, se sabe que la Real Academia Española (RAE) es una Institución creada en 1713, justo en una época en la que se tomó conciencia sobre la necesidad de mantener la esencial unidad del idioma español en todo el ámbito hispánico; por ello, fue propósito de la Real Academia "fijar las voces y vocablos de la lengua castellana en su mayor propiedad, elegancia y pureza". Y para progresar en esa empresa, la RAE ha cuidado desde entonces el código lexical (las otras formas de mantener la unidad son las prescripciones morfosintácticas y ortográficas). Es por esto que si se repara en el emblema de la RAE, se encuentra un crisol puesto al fuego, con la leyenda Limpia, fija y da esplendor. Es de notar, así, que es un brío constante para que la lengua sea purificada, un trabajo de eliminación del desperdicio a través de un reglado del buen decir.

Ahora, cuando se repara en los referentes presentes en el relato en relación con los diccionarios de la RAE, se comprueba qué información es fehaciente. Así, es sabido que desde 1925 la editorial madrileña Espasa-Calpe, fundada en 1860 con el interés de favorecer el desarrollo cultural de España y Latinoamérica, se ha encargado de publicar el Diccionario de la RAE (el DRAE), desde su Décima 
Quinta edición hasta la actualidad (Vigésima segunda edición, 2001).

Además de este diccionario usual, la RAE ha publicado cuatro ediciones de un Diccionario manual e ilustrado de la lengua española. La primera edición es de 1927; por cierto, con numerosas reimpresiones posteriores, mientras que la segunda edición es, efectivamente, de $1950 .{ }^{6}$ Cuando se repara en la intención de editar esta versión del diccionario, la del manual e ilustrado, se aspira a que llegue a un público más amplio, y para ello, este tipo de obras lexicográficas,

[...] simplifica y actualiza numerosas definiciones o acepciones, e incluye tecnicismos, neologismos y acepciones nuevas, a veces de uso restringido, que van marcadas mediante corchetes / Así pues, dado sus diferentes objetivos, cabría hipotizar una mayor apertura del Diccionario manual frente al usual a la hora de aceptar voces o significados nuevos de cualquier campo semántico, y también, por tanto, del ideológico. (Lozano, 2004, p.158)

Gracias a los servicios de la página oficial de la RAE (www.rae.es), es posible reparar, desde la sección del Nuevo Tesoro Lexicográfico de la Lengua Española (NTLLE) que contiene las imágenes digitalizadas de 68 obras lexicográficas desde el siglo $\mathrm{XV}$ hasta hoy (entre las que se incluyen todos los diccionarios de la Academia), y donde se puede indagar, para nuestro caso particular, las entradas perro y mujer con el fin de verificar cómo estas han evolucionado a lo largo de los últimos tres siglos. En este ejercicio, simplemente nos aferramos a la idea de que las realidades se apoyan en sus nombres $-\mathrm{y}$ viceversa-. Nos permitiremos, entonces, como parte del rastreo indicial, distinguir los detalles de la evolución de la definición, persiguiendo la misma forma que usó Morelli cuando indagaba ciertos rasgos pictóricos, ejemplo que el mismo Ginzburg (2008) nos trae, como arquetipos de lectura indicial. ${ }^{7}$ El Diccionario de la lengua

6 Después de esta han aparecido otras dos ediciones, la de 1983-1985 y la de 1989. castellana (Madrid, Imprenta de la Real Academia Española, por los herederos de Francisco del Hierro), definía perro de la siguiente manera:

Perro. m. Animal doméftico y familiár de que hai muchas efpecies y todos ladran. Unos firven para la guarda de las cafas y ganádos y otros para la caza; y fegún fus calidades, tamaños y propriedades, tiene diversos nombres que fe explicah en fus lugares. (DRAE, 1737, p.232,1)

Esta definición se mantiene igual por las siguientes cuatro ediciones y solo cambia en la Quinta edición, aparecida en 1817, cuando se puede leer un extenso artículo lexicográfico y lleno de detaIles sobre su aspecto físico, sus cualidades orgánicas, sus costumbres alimentarias, su función en relación con el hombre, entre otros aspectos:

Perro. s.m. Cuadrúpedo, que nos encuentra sino domésticado ó nacido de castas domesticadas, y que habiéndolo sido desde tiempo inmemorial, se halla tan alterado, que se ignora cuál haya sido su forma primitiva. Varía al infinito en el color, en la disposición de las orejas y hocico, en la forma de su cuerpo, en el tamaño, en fin en todo, si se exceptúa la cola, que en todas las castas está más o menos rollada hácia el lomo. La delicadeza y actividad de

7 Giovanni Morelli fue un médico italiano, igualmente entendido en pinturas, del siglo XIX. Entre 1874 y 1876 publica un tratado con el que se hace famoso, Un nuevo método para la atribución correcta de las pinturas de los viejos maestros, que suscita con su aparición controversia con otros historiadores del arte clásico. Morelli hace notar que los museos estaban llenos de pinturas atribuidas de manera errónea. Asignarlas correctamente siempre ha sido muy difícil, porque con frecuencia son pinturas sin firma, o han sido repintadas o restauradas de manera defectuosa; en consecuencia, distinguir una copia de un original no es tarea sencilla. Pero, lo que el italiano propone, entonces, es que hay que abandonar la tendencia habitual a privilegiar las características más obvias de una pintura, ya que estas son las más fáciles de imitar. Aquí está el arrojo de su método: había que concentrarse en los detalles menores, especialmente en los menos ligados al estilo típico de la escuela del pintor. Los elementos a prestarles especial atención serían, entonces, los lóbulos de las orejas, las uñas, la forma de los dedos de las manos y de los pies.

8 En adelante, se trascribe tal cual aparece en las ediciones consultadas del Nuevo Tesoro Lexicográfico de la Lengua Española (NTLLE), disponible en www.rae.es. 
su olfato, su gran docilidad, su instinto prodigioso y su fidelidad extraordinaria le han grangreado siempre y en todos los países los cuidados del hombre, que lo ha escogido por su compañero en la caza de los otros animales, por guarda de su casa y de sus ganados, y por defensor de su propia persona. Aliméntase de carnes y de legumbres; es voraz; engendra y comunica á los otros animales la enfermedad conocida con el nombre de rabia, y habita como el hombre en todos los países y climas conocidos. (DRAE, 1817, p.664,3)

En la Séptima edición vuelve a cambiar el contenido del artículo en mención y los criterios de definición se abrevian. Seis ediciones más adelante, y 67 años después, se encuentran nuevos cambios en la definición, ya muy cercanos a la que aparece en la Segunda edición del manual ilustrado que referencia el cuento de Cabrera:

Perro. (Del b. lat. canis petronius. Perro del gabado, del lat. petro, Carnero?) m. Mamífero carnicero, doméstico, de tamaño, forma y pelaje muy diversos, según las razas, pero siempre con la cola más o menos enroscada á la izquierda y de menor longitud que las patas posteriores, una de las cuales abre el macho para orinar. Tiene olfato muy fino y es inteligente y muy leal al hombre. (DRAE, 1899, p.769,2)

En la Décimo quinta edición (1925), hay cambios, pues se elide la información "[...] más o menos enroscada á la izquierda y [...]" en la referencia a una cualidad de su cola, además se sustituye el verbo "abre" por "alza", a propósito de las acciones de las patas de los machos al orinar. $Y$ con estos cambios, se mantiene el artículo lexicográfico hasta la Segunda edición ilustrada que, en su primera acepción, reza:

Perro. m. Mamífero carnicero doméstico, de tamaño, forma y pelaje muy diversos, según las razas, pero siempre con la cola de menor longitud que las patas posteriores, una de las cuales suele alzar el macho para orinar. Tiene un olfato muy fino $y$ es inteligente y muy leal al hombre. (DRAE, 1950, p.1173)

Entre tanto, la entrada lexicográfica mujer aparece por primera vez en la Séptima edición, así:

Mujer. f. Criatura racional del sexo femenino || La casada con relación al marido. (DRAE, 1832, p.502)

Esta definición se mantiene igual hasta la Décimo tercera edición, cuando se define así:

Mujer. (Del lat. muľer, -ēris). f. Persona del sexo femenino. (DRAE, 1899, p.680,2) ${ }^{9}$

Tras esta pesquisa, es bastante más claro el relato en cuestión. Cabrera Infante nuevamente se nos muestra como un especialista en maniobrar los significantes del(o) Otro, de modo que una determinada realidad, en sus manos, ya no es fiel y, en esa alteración de la alteridad, suscita a sus lectores un momento de tirantez, que es a la vez de confusión pasajera. Quedarse en ese plano de perturbación, implicaría, sin más, no comprender su verdadero juego-de-vocablos que, en este caso, comienza con la apropiación del poder (de la palabra) que forja el saber, aprovechando algo que ya ha hecho una institución de poder cultural, la RAE, con el ánimo de mostrar cómo el lenguaje es, al tiempo, el gestor y el mejor síntoma de las crisis humanas. Es así como se ve que la crítica a algo que, aparentemente no hace verdaderamente una institución cultural, puede hacerse para dejar allí una huella de su dificultad. Dicho en términos de Paz,

Todo período de crisis se inicia o coincide con una crítica del lenguaje. De pronto se pierde la fe en la eficacia del vocablo... cosas y palabras se desangran por la misma herida. Todas las sociedades han atravesado por estas crisis de sus fundamentos que son,

9 Asimismo aparece definida en la Edición de 1950 y, de hecho, es idéntica hasta la edición actual. 
asimismo y sobre todo, crisis del sentido de ciertas palabras... no sabemos dónde comienza el mal. Si en las palabras o en las cosas, pero cuando las palabras se corrompen y los significados se vuelven inciertos, el sentido de nuestros actos y de nuestras obras también es inseguro. (Paz, 2000, p.29)

Pues bien, notoriamente, el autor ajusta la definición de perro a la de mujer, al cambiar algunos significantes propios de la definición del primer evento por otros significantes, más o menos isomórficos en cuanto a la pertenencia del campo semántico, para re-definir el segundo evento. De esta suerte, los cambios operados son carnicero por omnívoro, cola por mamas, menor longitud por más pequeñas, patas posteriores por nalgas y macho por hembra. Con estos cinco trueques, aparentemente perversos, queda consumada la acción que altera todo el significado de su experimentación lexicográfica, generando un plus de sentido extraordinario: Cuadro 1.

Si se excluye el trueque de la información gramatical (m. por $\mathrm{f}$.), es fascinante encontrar que los cinco cambios ejecutados por el autor en la definición de perro para construir su definición de mujer se hacen corresponder con los cinco cambios en la definición que la RAE ha hecho de la entrada perro en un poco más de dos siglos, con el uso de 17 ediciones del diccionario Usual (también reflejados en ediciones del diccionario manual e ilustrado); todo esto, mientras que la entrada lexicográfica $m u$ jer presenta, a lo sumo, dos permutas en el mismo tiempo, cifradas en el mero cambio de "Criatura racional" por "Persona".
La pregunta que surge en este momento es, ¿cuál es la intención de este juego de sustitución significante que ejecuta Cabrera Infante? $\mathrm{O}$, dicho de otra forma, ¿cuál es la equivalencia, la forma de traducir el texto original $(X)$ a un texto latente $(Y)$ y poder afirmar la ecuación $X=Y$, y así levantar una hipótesis de sentido? Pues bien, tras todos estos rodeos, si se vuelve al relato, se puede encontrar que Cabrera, usando apenas la estrategia de una estructura condicional, genera una sutil pero magnífica crítica social. Entonces, respetando la grafía, tenemos:

SI LA RAE, A TRAVÉS DE SU FUNCIÓN DE PRECISAR VOCES DEL IDIOMA, CUMPLIERA SU OBJETIVO DE PURIFICAR UNA VOZ Y DARLE SU JUSTA HONRA Y ESTIMACIÓN, ENTONCES DEBERÍA PRECISAR Y DESIGNAR —DE UN MODO EFICAZ- QUE A LA MUJER SE LE CONCIBE (Y, EN CONSECUENCIA, SE LE TRATA) COMO A UN ANIMAL Y QUE PARA SER, DEBE ESTAR ANUDADA A UNA RELACIÓN CON UN OTRO.

Pero he aquí lo más interesante: no se trata de cualquier animal, ya que la metáfora zoológica de perra es bastante usual en el ámbito de las relaciones entre hombres y mujeres, la mayor de las veces con el sentido de prostituta, y todo lo que ello asocia en la negatividad de su imagen. De esta forma, el orbe de lo femenino pasa de tener el estereotipo de maternal y delicada, fuerza del bien y ángel del hogar, a ser potencia del mal, asociada con el salir de la esfera privada y usurpar actividades que no le son culturalmente atribuidas. Entonces, se le encierra, se le quema viva, se le castiga, se le lanzan oprobios, se le subestima, se le amaestran

Cuadro 1. Acoplamiento de la definición de perro al de mujer

\begin{tabular}{ll}
\hline \multicolumn{1}{c}{ Diccionario Manual, 1950 } & \multicolumn{1}{c}{ Exorcismos de Esti(I)o, 1976 } \\
\hline Perro. m. Mamífero carnicero doméstico, de tamaño, for- & Mujer 1. f. Mamífero omnívoro doméstico, de tama- \\
ma y pelaje muy diversos, según las razas, pero siempre & ño, forma y pelaje muy diversos, según las razas, pero \\
con la cola de menor longitud que las patas posteriores, & siempre con las mamas más pequeñas que las nalgas, las \\
una de las cuales suele alzar el macho para orinar. Tiene & cuales suele asentar la hembra para orinar. Tiene oído \\
un olfato muy fino y es inteligente y muy leal al hombre. & muy fino y es inteligente y muy leal al hombre. \\
\hline
\end{tabular}

Fuente: elaboración propia. 
conductas, se le marca su carne con moretones y se le insulta con vilezas como monstruo, bruja, malvada, fiera indomable, animal en celo.

Estos son mecanismos frecuentes tanto en el lenguaje coloquial como en el poético, donde por irradiación metafórica del campo semántico 'animal', se fundamenta algo del campo de lo 'humano', tanto para mujeres como para hombres, entre otras razones porque las metáforas zoomórficas guardan una semejanza amplia con el resto de tratamiento metafórico del discurso cotidiano. $\mathrm{Y}$ es que los aspectos de la forma-de-ser humana siempre se han asociado con determinados animales: la astucia con el zorro, la necedad con el asno, etcétera. Incluso las partes del animal (aves, peces, reptiles, etcétera) irradian metaforizaciones, a veces de forma enigmática como es el caso de la garra del gato con la mujer, puesto que es oculta, hipócrita, forrada y presenta una suavidad exterior excitante, y la garra de las aves con el hombre ya que es desnuda, franca, tal como lo establece explícitamente Nietzsche en su Zaratustra. Los hombres dicen, entonces, de la mujer que es zorra, lora, burra, cotorra, loba, gata, etcétera. Y también lagarta, víbora o arpía. Todo esto, mientras que no existe un equivalente, en cuanto a los despreciativos aplicados al hombre, que revele tanta abundancia como con el campo semántico de los 'peces marinos'. Un hombre, por caso, puede ser imaginarizado como delfín (en política) o un tiburón (de la banca), aunque también un dinosaurio (en la universidad o en su lugar político); pero, en todo caso, con frecuencia no pasa de ser un cerdo y un perro.

De esta forma, Cabrera desea levantar una crítica a la condición femenina, un problema que, todos sabemos, no tiene nada de superficial, porque está marcado por estereotipos y prejuicios heredados de la antigüedad como la subyugación, la subordinación, la pasividad y la animalización, las que testarudamente persisten, incluso en una época como la década de 1950, elegida por Cabrera para avanzar su diatriba bajo la excusa de la publicación de la segunda edición del Diccionario
Manual, pues es sabido que esta década marca el nacimiento de una segunda ola en el feminismo de Occidente y, con ella, algo de alivio para la igualdad de géneros y la rotura de prejuicios. Así, pues, una posible lectura en clave interpretativa del relato in-titulado es que la mujer es mal-tratada, muy a pesar de los avances de su condición socio-política y cultural generados por el movimiento feminista, y esta situación parece no estar eximida en los bien-tratados documentos de la RAE, que más bien persisten en eternizar la involución de su condición frente a sí y frente al otro — sexual—.

Aquí se evidencia cómo detrás de estas acciones de poder, una institución que vela por la pureza y elegancia de la lengua y declara sus esfuerzos "al servicio y honor de la nación", contribuye, más bien, a sostener realidades sociales y a construir subjetividades con evidentes oposiciones conceptuales como, por ejemplo, /razón/ versus /emoción-instinto/; /animal/ versus /humano/, /erudito/ versus /bestia/, /cultura/ versus /naturaleza/, etcétera (Pastor, 1998). Es en este sentido, ser mujer es una recreación moldeada por valores, creencias y pautas de conducta que manifiestamente alimentan las instituciones sociales (familia, nación, RAE), pues, finalmente mujer es, ante todo, una representación social cristalizada en un vocablo sígnico que circula por el mundo histórico y se encarna en un sujeto histórico sexuado:

El género es, en todas las sociedades conocidas, un principio básico de organización social, como la clase social o el concepto de jerarquía. Sin embargo el género, como la marca racial, se asigna de por vida y es inamovible al contrario de la clase y el acceso al poder. Es decir, que la distinción hombre-mujer se considera universal y esta oposición binaria domina las clasificaciones sociales. Dentro de la organización social, el género es un sistema simbólico o semántico en línea con las propuestas teóricas del lingüista Ferdinad de Saussure que demuestra cómo en el lenguaje, en nuestra vida construimos significado mediante oposiciones binarias blanco-negro, hombre-mujer, razón-naturaleza, etcétera [...] La 
teoría posestructuralista se hace eco de la importancia del lenguaje como vía de construcción de la identidad individual o subjetiva y la identidad colectiva. (Jaramillo, 2003, p.290)

En este sentido, no es gratuito que, incluso, históricamente, la entrada perro, en las ediciones de los diccionarios (usual y manual), haya mutado más veces que la entrada mujer, que no gratuitamente ha permanecido fija, esto es, sin evolución y que con cierta intención se define de forma muy escueta, evidenciando la falta de propiedad y esplendor y que, más bien, se delinea en algunas enunciaciones históricas de perro puestas en sendos artículos lexicográficos, como en la edición de 1817. Esta cuestión no es para nada exagerada, pues cuando se repara en la realidad social de potencias como Estados Unidos, se tiende más a glorificar, dar esplendor y ennoblecer a los perros que a los seres humanos mismos, tal como se observa actualmente donde en muchos hogares hay un perro, cuyo bienestar es sagrado, hasta el punto de convertirse en una enfermiza obsesión.

Ahora bien, a propósito del título como un indicio más de los previstos en la labor lectora, es sabido que al no tener título el relato, digamos mejor, al no tener nombre ${ }^{10}$ lo que allí se describe, establece un acto lingüístico que intenta conjurar o exorcizar esas formas o estilos de concebir a las mujeres y degradarlas en su condición; incluso de conjurar esas costumbres y prácticas (estilos) milenarias que las reducen a seres cercanos a las hembras animales, que despiertan solo vehemencia pasional, agitación o calor (estío) ${ }^{11}$ y, por tanto, que solo sirven para los placeres de la cama o para inspirar literatura sublime que solo parece tender resplandor en la ficción, pero no en el mito. ${ }^{12}$

10 La expresión coloquial "(Esto) no tiene nombre", se usa frecuentemente para dar a entender que una acción es tan reprochable que no se quiere o no se puede calificar.

11 La palabra estío viene del latín aestatatis, que significa verano y cuya base etimológica es aestus, que significa calor ardiente, vehemencia, agitación.

12 El mismo Cabrera Infante reconoce que literatura tiene como base etimológica francesa la estructura Lit, que significa cama.

\section{A MANERA DE CONCLUSIÓN}

Es así como a través del texto de Cabrera Infante y, explotando sistemáticamente cuatro huellas textuales que se diagnosticaron como elementos indiciarios, se ha sacado a la luz un hecho por todos reconocido y reservado en la memoria cultural: el ultraje que han padecido - y padecen - las mujeres por el hecho de ser definidas, esto es, delimitadas desde el ámbito de la animalidad. Este relato sería, entonces, una forma estética amparada de una compleja fórmula crítico-paródica, para desarrollar una forma de d-enuncia sobre la o-presión y ab-uso al género femenino. Y su juego con los significantes, bajo la imitación del trabajo cultural de la RAE (limpia, fija y da esplendor), saca a flote su ideología en relación con la mujer. Es así como, sin más, este tipo de texturas permite un trabajo de arreglo significativo, simulando el poder de la palabra que la RAE posee, con lo cual la crítica es doble: por un lado la situación de la mujer; por otro la marmórea forma de fijar voces en la lengua y por tanto en el pensamiento colectivo, históricamente preservado.

\section{RECONOCIMIENTOS}

Este artículo hace parte del proyecto investigativo Textos creativos y la identidad social en Colombia (2013-2014), auspiciado por Centro de Investigaciones y Desarrollo Científico (CIDC) de la Universidad Distrital, FJC; código 4-543-384-13.

\section{REFERENCIAS}

Baquero, P. (2006). La investigación en el aula en la universidad. Aportes para una revisión crítica. En D. Santos., P. Baquero, M. Molano y M. Pardo. Prácticas pedagógicas universitarias: aproximaciones para su comprensión (53-96). Bogotá: Universidad de la Salle.

Braslavsky, B. (2013). Enseñar a entender lo que se lee. Buenos Aires: Fondo de Cultura Económica.

Bolívar, A. (Comp.) (2007). Análisis del discurso: ¿por qué y para qué? Caracas: Universidad Central de Venezuela. 
Cabrera Infante, G. (2006) Tres tristes tigres. Edición especial. Bogotá: Editorial Planeta Colombiana; Madrid: Espasa.

Cabrera Infante, G. (1976) Exorcismos de Esti(I)o. Barcelona: Seix Barral.

Cairney, T. (1992). Enseñanza de la comprensión lectora. Madrid: Ministerio de Educación y Ciencia.

Cajiao, F. (2014, abril 7). Otra vez Pisa. El Tiempo. Recuperado de http://www.eltiempo.com/opinion/ columnistas/otra-vez-pisa-francisco-cajiao-columnista-el-tiempo/13798017

Cárdenas, A. (2006). Sentido y discurso. Para leer mejor. En L. A. Ramírez Peña, y G. L. Acosta Valencia (Eds.). Estudios del discurso en Colombia (295311). Medellín: ALED.

Carlino, P. (2007). Escribir, leer y aprender en la universidad. Una introducción a la alfabetización académica. Buenos Aires: Fondo de Cultura Económica.

De Beaugrande, R. (2002). Curso internacional de análisis del discurso en las ciencias sociales, la cultura y el territorio. Memorias. Bogotá: Instituto Caro y Cuervo y Universidad Nacional de Colombia.

Eco, U. (1981). Lector in fábula. Madrid: Lumen.

Eco, U. (1986). La estructura ausente. Madrid: Lumen.

Eco, U. (1992). Los límites de la interpretación. BarceIona: Lumen.

Ferreiro, E. y Gómez, M. (1986). Nuevas perspectivas sobre los procesos de lectura y escritura. México: Siglo XXI.

Flórez, R. y Gómez D. (2013). Leer y escribir en los primeros grados: retos y desafíos. Bogotá: Universidad Nacional de Colombia.

García-Dussán, É. (2008). Manual de hifología. Análisis e interpretación de textos. Bogotá: Unisalle Ediciones.

Ginzburg, C. (2008). Indicios. Raíces de un paradigma de inferencias indiciales. En Mitos, emblemas e indicios (3-56). Barcelona: Gedisa.

Goodman, K. (1996). La lectura, la escritura y los textos escritos: una perspectiva transaccional sociopsicolingüística. Textos y Contextos, 2, 134-187.

Jaramillo Jiménez, J. E. (Comp.) (2003). Cultura, identidades y saberes fronterizos. Bogotá: Colección CES.
Jolibert, J. y Sraïki, C. (2006). Niños que construyen su poder de leer y escribir. Buenos Aires: Manantial.

Klinkenberg, J. M. (2006). Manual de semiótica general. Bogotá: Universidad de Bogotá Jorge Tadeo Lozano.

Lerner, D (1985). La relatividad de la enseñanza y la relatividad de la comprensión. Lectura y vida. Revista Latinoamericana de Lectura. 6(4), 34-52.

León, J. (2003). Conocimiento y discurso. Claves para inferir y comprender. Madrid: Pirámide.

Linares, A. (2013, mayo 24). Colombia enfrenta una alarmante brecha en la calidad educativa. El Tiempo. Recuperado de http://www.eltiempo.com/ archivo/documento/CMS-12822612

López, G. (2002). La metacomprensión y la lectura. En M. C. Martínez (Comp.). Propuesta de intervención pedagógica para la comprensión y producción de textos académicos. Cali: Universidad del valle.

Lozano, M. (2004). Guerra, terrorismo e ideología en los diccionarios de la Real Academia Española. AISPI, Actas 22. Centro Virtual Cervantes.

Mac Adam, A. (1996). Entrevista a Guillermo Cabrera Infante. En Escritores latinoamericanos. Los reportajes de The Paris Review (45-59). Buenos Aires: El Ateneo.

Maya, G. (2013, agosto 30). Educación: no es culpa de los maestros. El Espectador, 1-13.

Medina, J. y Bruzual, R. (2006, noviembre). Concepción de la escritura y métodos empleados para su enseñanza ciencias sociales. Ciencias Sociales Online, 3(3), 1-13. Recuperado de http://www. uvm.cl/csonline/2006_3/pdf/concepcion $\% 20$ de $\% 20$ escritura $\% 20 y \% 20$ metodos\%20de\%20ense\%F1anza.pdf

Molina, V. (2012). Tensiones entre discursos de estudiantes y profesores universitarios sobre la lectura y la escritura. Signo y Pensamiento 61(31) 126-141.

Nuevo Tesoro Lexicográfico de la Lengua Española (NTLLE). (S.f.). Recuperado de www.rae.es

Osses, S. (2008). Metacognición: un camino para aprender a aprender. Estudios Pedagógicos, 34(1), 187-197. 
Pastor, R. (1998). Asimetría genérica y representaciones del género. En: J. Fernández. Género y sociedad (12-48). Madrid: Pirámide.

Paz, O. (2000). El arco y la lira. Bogotá: Fondo de Cultura Económica.

Pérez, M. y Rodríguez, A. (2012). ¿Para qué se lee $y$ se escribe en la universidad colombiana? Caracterización de prácticas de lectura y escritura en 17 universidades. Revista de Docencia Universitaria, 11(1), 137-160.

Popper, K. (1977). La lógica de la investigación científica. Madrid: Tecnos.
RAE (S.f.). Nuevo tesoro lexicográfico de la lengua española. Recuperado de http://ntlle.rae.es/ntlle/ SrvltGUILoginNtlle

Schön, D. (1992). La formación de profesionales reflexivos. Barcelona: Paidós.

Smith, F. (1984). Comprensión de la lectura. Análisis psicolingüístico de la lectura y su aprendizaje. México: Trillas.

Solé, I. (1992). Estrategias de lectura. Barcelona: Graó. van Dijk, T. A. (1995). De la gramática del texto al análisis crítico del discurso. BELIAR (Boletín de Estudios Lingüísticos Argentinos), 2(6), 12-34. 